\title{
Cost driver analysis of statin expenditure on Australia's Pharmaceutical Benefits Scheme
}

Thai LP ${ }^{1}$, Moss $\mathrm{JR}^{2}$,Godman B $\mathrm{B}^{3,4^{*}}$, Vitry Al'

${ }^{1}$ Quality Use of Medicines and Pharmacy Research Centre, Sansom Institute, University of South Australia, GPO Box 2471, Adelaide, South Australia, 5001. Emails: loc.thai@mymail.unisa.edu.au; agnes.vitry@unisa.edu.au

${ }^{2}$ School of Public Health, University of Adelaide, North Terrace, Adelaide, South Australia, 5005.

Email: john.moss@adelaide.edu.au

${ }^{3}$ Division of Clinical Pharmacology, Karolinska Institutet, Stockholm, Sweden. Email address:

Brian.Godman@ki.se

${ }^{4}$ Strathclyde Institute of Pharmacy and Biomedical Sciences, Strathclyde University, Glasgow, Scotland. Email: Brian.Godman@strath.ac.uk.

\section{*Author for correspondence}

(Accepted for Publication in Expert Review of Pharmacoeconomics and Outcomes Research Please keep CONFIDENTIAL)

\begin{abstract}
Introduction: The Australian Pharmaceutical Benefits Scheme (PBS) provides universal access to subsidised medicines. In 2013, statins as a class had the highest expenditure on the PBS.

Objectives: To assess the influence of policies and drivers affecting PBS statin utilisation and expenditure between 1992 and 2013. Methods: Analyses conducted from 1992 to 2013 and over three distinct time periods, including monthly expenditure/prescription, annual utilisation (calculated as Defined Daily Doses/1000 inhabitants/day) and statin strengths dispensed. Results: The major driver of increased PBS expenditure for statins was increased volumes. After adjusting for inflation, the average PBS expenditure on statin prescriptions was the major negative driver. Other influential drivers included the increased use of newer statins and increased strength of statins dispensed. Discussion: Whilst the inflation-adjusted reimbursed price of statins decreased, increased utilisation, including increased use of patented statins, increased total statin expenditure. Successful measures adopted by other countries could be applied to Australia to decrease total medicines expenditure.
\end{abstract}

Key words: Australia, demand-side measures, drug utilisation research, generics, guidelines, pharmaceutical expenditure, prices, statins

\section{Background}

In 2013, cardiovascular disease was the largest cause of death globally, including within Australia [1]. The use of lipid lowering medicines to treat high blood cholesterol levels and reduce cardiovascular disease has increased appreciably over the last decade [2], helped by guidelines endorsing their use following multiple studies demonstrating a reduction in morbidity and mortality [3-8]. In 2011, Australia had one of the highest consumptions per capita of lipid lowering medicines (137 Defined Daily Doses (DDD) per 1,000 people per day) compared to other Organisation for Economic Co-operation and Development (OECD) countries (OECD average 91 DDD per 1,000 people per day) [2, 8]. In 2013, lipid lowering medicines contributed the highest costs of any Anatomical Therapeutic Classification (ATC) drug group to the Australian government at AUD 1.33 billion overall, representing an increase of 52\% from 2002 where total spending on this group was AUD 873.7million (in 2013 AUD) [9, 10]. Notably, the class of statins accounted for $90 \%$ of overall spending on lipid lowering medicines in $2013[9]$.

Several studies have shown that the prices for statins have been higher in Australia compared to other countries [11-13]. In early 2012, the wholesale price of simvastatin $40 \mathrm{mg}$ in Australia was the most expensive when compared with 13 other OECD countries, and was still the third most expensive after a price decrease in 2012 [11]. In 2011-12, the price of atorvastatin was $96 \%$ higher in Australia than in New Zealand [12].

In addition to prices, the relative utilisation of cheaper off-patent generic statins compared to more expensive patent-protected statins also had a strong impact on total expenditure. Simvastastin and pravastatin were the first statins marketed in Australia, and lost patent protection in 2004 and 2005 
respectively. Atorvastatin and rosuvastatin remained patent protected until 2012 and 2013 respectively. The relative utilisation of patent-protected statins was shown to be greater in Australia than in the USA and some European countries with active policies to enhance the prescribing of generic statins $[13,14]$. In the USA, only approximately $35 \%$ of the total statin market share was accounted for by patent-protected atorvastatin and rosuvastatin four years after simvastatin patent expiry [15]. In Germany, patented statins accounted for just $2.4 \%$ of total statins following the introduction of a 'jumbo' class for all statins $[14,16]$. In three countries with multiple policies to enhance the prescribing of generic versus patented statins, patented statins accounted for $21 \%$ of total statins in Sweden in 2007, 39\% in the Netherlands in 2010 and 40\% in Scotland in 2010 [8, 14, 17]. In contrast, four years after the simvastatin patent expiry in Australia, $70 \%$ of all statin prescriptions on the PBS were for the more expensive patented atorvastatin and rosuvastatin [13]. This difference in utilisation patterns for statins was estimated to have cost Australia AUD $\$ 1.1$ billion compared to potential expenditure if statin utilisation patterns in Australia more closely resembled those in England in those four years [13].

Expenditure on statins was lowered in the Netherlands, Sweden and the UK by the price of generic simvastatin being as low as $2 \%$ to $4 \%$ of the price prior to patent expiry through government interventions. These include preference pricing policies in the Netherlands, compulsory generic substitution with the lowest price molecule in Sweden, and high international non-proprietary name (INN) prescribing coupled with transparency in the pricing of generics in the UK [8, 17-19]. This expenditure control was helped by health authorities across Europe typically viewing all statins as therapeutically equivalent at appropriate doses [8,16, 17, 20-22]. Recent studies including one in Australia have shown that lower out of pocket costs for patients increase compliance, which can lead to lower cardiovascular event rates [23, 24].

In Australia, a number of supply side and demand side policies have been implemented to control expenditures on medicines listed on the Pharmaceutical Benefits Scheme (PBS), the national public pharmaceutical insurance scheme. Since 2005, new major pricing policies have included a $16 \%$ price reduction for medicines upon the entry of the first generic version, separation of the PBS into two different formularies ( $\mathrm{F} 1$ containing non-equivalent patent protected medicines and F2 containing medicines with equivalents or generics) and the introduction of price disclosure [12, 25]. Price disclosure for medicines on F2 mandates that manufacturers provide data on the ex-manufacturer price of medicines to the government, with adjustments to the PBS price if the average weighted disclosed price of medicines is more than 10 per cent cheaper than the ex-manufacturer price on the PBS.

Demand side policies have also been implemented for prescribers, pharmacists and patients. There are brand or therapeutic group premiums paid by the patient for brands with higher prices than the lowest priced brand [26, 27].

Generic substitution is allowed at the pharmacy level, with fees paid to pharmacies to dispense medicines which do not attract extra price premiums and there are public information campaigns run by the National Prescribing Service (NPS) [28, 29]. These policies have been collated under the 4 Es - Education, Economics, Engineering and Enforcement [30], with this approach successfully used within and across countries and medicine classes to compare and contrast the influence of different demand side measures on both new and established medicines [14, 17, 31-35]. Policies influencing the prescribing of generics versus originators in Australia are included in Table 1. In contrast, the Pharmaceutical Benefits Advisory Committee (PBAC, the committee which assesses listing of medicines on the PBS) considered atorvastatin and rosuvastatin to have a better efficacy than simvastatin on two different occasions, first in July 2005 and then in 2012 during a review of statin therapies [36]. 
Table 1 - Australian demand side policies to influence the prescribing of generics

\begin{tabular}{|c|c|c|}
\hline Category & Definition & Examples in Australia \\
\hline Education & $\begin{array}{l}\text { Programs influencing the } \\
\text { prescribing and dispensing of } \\
\text { generic medicines }\end{array}$ & $\begin{array}{l}\text { Public campaigns regarding generic medicines } \\
\text { efficacy and safety }\end{array}$ \\
\hline Engineering & $\begin{array}{l}\text { Organisational and } \\
\text { managerial interventions that } \\
\text { influence change }\end{array}$ & $\begin{array}{l}\text { Prescribing software that automatically allows for } \\
\text { brand substitution } \\
\text { Pharmacist initiated brand substitution allowed }\end{array}$ \\
\hline Economics & $\begin{array}{l}\text { Financial interventions to } \\
\text { promote the use of cheaper } \\
\text { medicines }\end{array}$ & $\begin{array}{l}\text { Brand price premiums for a number of medicines } \\
\text { Financial incentive to pharmacist to dispense } \\
\text { medicines without brand price premiums }\end{array}$ \\
\hline Enforcement & $\begin{array}{l}\text { Regulations which include } \\
\text { those enforced by law }\end{array}$ & None currently in Australia \\
\hline
\end{tabular}

A number of studies have assessed the prices and usage of statins in Australia compared with other countries [12,13]. However, all these studies had a cross-sectional design and did not examine the impact of policies over time. This study aimed to assess the influence of policies and drivers affecting PBS statin utilisation and expenditure between 1992 and 2013. It also examined the drivers of statin expenditure with regard to the relative effect of prices, usage, and changes to strengths and types of statins used over time. The large utilisation and total cost to the PBS for supplying statins makes them an excellent case study for examining the effects of government interventions in the medicines market in Australia.

\section{Methods}

- Funding timeline of statins

A review of funding decisions relating to the listing and pricing of statins on the PBS was undertaken using PBAC outcome summary documents, past versions of the PBS schedule and Department of Health documents [36-39]. A timeline encompassing all the decisions about statins on the PBS including the listing, price changes and restrictions on availability was documented.

\section{- Expenditure and volume data sources}

Total expenditure and prescription data were obtained from the PBS items report website [40]. This database covers all prescription volumes and expenditure for medicines that are reimbursed by the Australian Government, but does not cover under co-payment nor private prescriptions [41]. Total statin expenditure per month from 1992 to 2013 was calculated and adjusted for inflation. All dollar values were adjusted for inflation using the Consumer Price Index for each quarter and linear interpolation across every three month period was applied [42].

- Drivers of PBS statin expenditure

Cost driver analysis was conducted to determine the factors which impact upon total statin expenditure. The drivers of statin expenditure on the PBS were estimated by adapting the methodology from the Patented Medicine Prices Review Board (PMPRB) in Canada [43]. The effect of each specific driver can be captured through this methodology as it compares two time periods and isolates the effect of the change in a specific factor by holding the other factors constant at the baseperiod value [43]:

$t:$ Time period

$$
X(t)=\sum_{i_{s, m}} p\left(i_{s, m}, t\right) \times \alpha\left(i_{s, m}, t\right) \times \beta\left(i_{m}, t\right) \times Q(t)
$$

$X(t)$ : Total expenditure in time period $t$

$p\left(i_{s, m}, t\right)$ : The average expenditure per prescription for product $i$ on the PBS of a certain strength-form combination $(s)$ and molecule $(m)$ in time period $t$

$\alpha\left(i_{s, m}, t\right)$ : The share of quantity for product $i$ over the sum of quantities for all medicines with the same active ingredient in time period $t$

$\beta\left(i_{m}, t\right)$ : The share of the sum of quantities for statins with the same active ingredient over the sum of quantities for all statins in time period $t$

$Q(t)$ : Total number of prescriptions in time period $t$

Changes in PBS expenditure on statins are attributed to the drivers which are summarised below: 
- Price effect: captures the impact of changes to the price the Government pays for statins

- Strength effect: captures the impact of shifting utilisation towards different strengths or formulations of a molecule (active ingredient)

- Switch effect: captures the impact of shifts in market shares between statins that are available in both time periods analysed

- New statin effect: captures the impact of shifts in utilisation of statins that have entered the market in the second time period and were not present in the first time period

- Volume effect: captures the impact of changes in the number of prescriptions dispensed to the population

Between two time periods the difference in total expenditure: $X(1)-X(0)=$

- Price effect

- Strength effect

- New statin effect

- Volume effect
- Switch effect

$$
\begin{gathered}
\sum_{i_{s, e, m}}\left[p\left(i_{s, m}, 1\right)-p\left(i_{s, m}, 0\right)\right] \times \alpha\left(i_{s, m}, 0\right) \times \beta\left(i_{m}, 0\right) \times Q(0)+ \\
\sum_{i_{s, e}, m} p\left(i_{s, m}, 0\right) \times\left[\alpha\left(i_{s, m}, 1\right)-\alpha\left(i_{s, m}, 0\right)\right] \times \beta\left(i_{m}, 0\right) \times Q(0)+ \\
\sum_{i_{s, e} m} p\left(i_{s, m}, 0\right) \times \alpha\left(i_{s, m}, 0\right) \times\left[\beta\left(i_{m}, 1\right)-\beta\left(i_{m}, 0\right)\right] \times Q(0)+ \\
\sum_{i_{s, e n, m}} p\left(i_{s, m}, 1\right) \times \alpha\left(i_{s, m}, 1\right) \times \beta\left(i_{m}, 1\right) \times Q(0)+ \\
\sum_{i_{s, m}} p\left(i_{s, m}, 0\right) \times \alpha\left(i_{s, m}, 0\right) \times \beta\left(i_{m}, 0\right) \times[Q(1)-Q(0)]
\end{gathered}
$$

Individual effects derived from the use of this methodology may explain most but not all the changes in total PBS expenditure for statins. The effect of each factor is calculated with the assumption that all other factors remain unchanged over the time period analysed. In reality, multiple factors change simultaneously, creating residual effects or cross effects [43].

An analysis of drivers was conducted firstly over the whole period from 1992 to 2013. In addition, three shorter-period analyses were conducted. From 1992 to 1996, the introduction of new statins on the PBS may have obscured and distorted the drivers, and so was not separately analysed. The shorter-period analyses were thus conducted consecutively from 1997. The first of these shorter time periods was from 1997 to 2005 and assesses the impact of the introduction of atorvastatin compared to the other statins. The second such time period was from 2006 to 2010 and assesses the impact of the first changes to the PBS pricing policies. The third such time period was from 2011 to 2013 and assesses the impact of the PBS reforms and PBS expenditure on statins. The individual drivers were assessed separately, including the use of statins, average PBS expenditure per statin prescription and the average strength of statins dispensed on the PBS. Cost driver analyses were conducted over calendar year periods to standardise all price, volume, inflation and population data sets that were available across consistent 12 month periods.

- Use of statins (Volume and switch effect)

Utilisation of all statins was calculated in DDD/1,000 inhabitants/day (DIDs), the international unit of drug utilisation [44, 45]. The DDD index for statins was changed in 2009 (the new DDD for atorvastatin was $20 \mathrm{mg}$ instead of $10 \mathrm{mg}$, the new DDD for simvastatin was $30 \mathrm{mg}$ instead of $15 \mathrm{mg}$ ) [46]. Analyses in the study used the 2009 DDDs across the entire study period to standardise the doses of statins [47, 48]. A sensitivity analysis was conducted using historical DDDs. The total population for each 12 month period was obtained from the Australian Bureau of Statistics [49]. Fixed dose combinations which contain statins were included in the overall utilisation analysis, as well as in a separate analysis of the fixed dose combinations market.

- Monthly PBS expenditure per statin prescription (Price effect)

For every month over the study period, PBS expenditure per prescription for each statin was calculated. There is a seasonal variability in the expenditure per prescription data due to the availability of the safety net for PBS prescriptions. This creates variability by month in the number of prescriptions dispensed and also in government expenditure on statins over the study period. Concession patients do not pay a co-payment for medicines when they reach the safety net, while general patients pay only the concession co-payment when they reach the safety net. Towards the end of each calendar year, patients who have reached the safety net tend to seek multiple supplies of their medicines at the cheaper cost to decrease out-of-pocket payments in the coming year. The Government subsidises a larger relative cost for patients on the safety net which can skew the analysis on expenditure per prescription. 
- Interrupted time series analyses

Interrupted time series analyses are used to study data that is collected at multiple points in time before and after an intervention to detect whether or not the intervention has had a significant impact on the underlying trend [50]. Segmented regression analyses were conducted on this data using regressions with autocorrelated errors to analyse the impact of PBS reforms and other pricing changes in the levels and trends in prices for all statins. These analyses are used to assess the slopes of two contiguous line segments before and after an intervention to determine whether there has been a statistically significant change in the slope. This method was used to provide a statistical test analysing the effect of PBS pricing policies on the expenditure per prescription for statins. The analyses were conducted for expenditure per prescription for each month, with the model taking into account the safety net effect. These analyses allow determination of whether the intervention had led to a statistically significant change in expenditure per prescription, but it was not possible to quantify the change. The analyses were conducted using SAS Enterprise Guide Version 5.1.

The estimated base model for the regressions was:

$$
Y_{t}=\beta_{0}+\beta_{1} \text { time }+\beta_{2} \text { intervention }+\beta_{3} \text { time after intervention }
$$

$Y_{t}$ is the mean expenditure per prescription for the time period $t$, time is a continuous variable indicating time in months from the start of the study period, intervention is a dummy variable with time t occurring prior to the price change (value for intervention $=0$ ) and after the price change (value for intervention $=1$ ). Three change points were used in this study, August 2005, August 2007 and April 2012, where changes to the price of statins on the PBS occurred due to implemented policies.

Time series analyses are the strongest and most commonly used design to assess the impact of an intervention where a randomised control trial is not possible [50-52]. The analysis can be used to detect whether or not an intervention had a significantly greater effect than the underlying trend by comparing time trends before and after the intervention [50,53,54]. One of the weaknesses for interrupted time series analyses is that they require multiple data points to reduce the variability and outliers [55]. This weakness was counteracted by having monthly data points to decrease variability and confirm the presence of a trend. Other factors which may affect validity include outcome coding, co-interventions or changes to the population under study [56].

- Strength effect

Average strength per prescription for each statin dispensed was calculated by using the formula below:

$$
\text { Average strength }=\frac{\left.\sum \text { (Number of prescriptions of each strength } \times \text { Strength of prescription }\right)}{\text { Number of prescriptions }}
$$

\section{Results}

- Summary of events

Simvastatin was the first statin listed on the PBS in 1990, followed by pravastatin in 1993 and fluvastastin in 1996 (Table 2). In 1998, atorvastatin was listed on the PBS on a cost-minimisation basis with simvastatin and pravastatin. As mentioned earlier, in July 2005 the listing was changed to cost-effectiveness on the basis that the PBAC concluded that atorvastatin was more effective than simvastatin in lowering LDL-cholesterol, justifying a relative price difference of $12.5 \%$ [36]. In 2006, rosuvastatin was the latest statin to be listed on the PBS - on a cost-minimisation basis with atorvastatin. In 2012, a review of the scientific evidence on statin therapies concluded that the price differential of $12.5 \%$ was still acceptable [36]. However, at that time, the actual price differential was about $30 \%$ above the original price differential considered to be cost-effective because the prices of off-patent simvastatin and pravastatin had decreased [36]. 


December 1990
June 1993
January 1996
January 1998

December 2004 January 2005 July 2005

August 2005

December 2005

February 2006

October 2006

December 2006

August 2007

August 2008

September 2009

April 2012

May 2012

December 2012

June 2013

August 2013

December 2013
Simvastatin first listed on PBS

Pravastatin first listed on PBS

Fluvastatin first listed on PBS

Atorvastatin first listed on PBS on a cost-minimisation basis with simvastatin and pravastatin

( $10 \mathrm{mg}$ atorvastatin $=20 \mathrm{mg}$ simvastatin $=20 \mathrm{mg}$ pravastatin $)$

Statin therapeutic group established including atorvastatin, simvastatin and pravastatin

First generic brand of simvastatin listed on PBS

$24 \%$ increase in patient co-payment

Atorvastatin listing changed from cost-minimisation to cost-effectiveness based on data showing atorvastatin being more effective than simvastatin in lowering LDL-cholesterol and a relative price difference of approximately $12.5 \%$

$12.5 \%$ price reduction applied to simvastatin and pravastatin due to new generic brands being listed

First generic brand of pravastatin listed on PBS

First fixed dose combination containing simvastatin PBS listed

Changes to eligibility for cholesterol lowering medicines including statins on the PBS to include patients with existing comorbidities

Rosuvastatin first listed on PBS on a cost-minimisation basis with atorvastatin

(10mg rosuvastatin $=30 \mathrm{mg}$ atorvastatin)

First fixed dose atorvastatin combination with amlodipine was listed

First fixed dose simvastatin combination with ezetimibe was listed

$20 \%$ price reduction to simvastatin offered by manufacturers, also applied to pravastatin via therapeutic groups

$25 \%$ F2T price reductions for simvastatin and pravastatin due to high level of discounting in community

Higher potency statin therapeutic group established which contains atorvastatin and rosuvastatin

EAPD first cycle price reductions for simvastatin (55.6\%) and pravastatin

$(49.94 \%)$

Statin therapeutic group containing simvastatin and pravastatin abolished

First generic brand of atorvastatin listed on PBS

$16 \%$ mandatory price reduction for atorvastatin due to new brands being listed on the PBS

$16 \%$ price reduction for rosuvastatin due to therapeutic group with atorvastatin

Review of Statin Therapies report released after request made in the Senate 22 November 2010

$25 \%$ price reduction to atorvastatin offered by manufacturers

$20.81 \%$ price reduction for rosuvastatin due to atorvastatin bench marking

First generic brands of rosuvastatin listed on PBS

Expanded and Accelerated Price Disclosure second cycle price reductions for simvastatin (44.66\%) and pravastatin (34.08\%)

Expanded and Accelerated Price Disclosure first cycle price reduction for atorvastatin $(50.06 \%)$

- Total PBS expenditure on statins

In real terms (2013 dollars), total PBS expenditure on statins was AUD 139.8 million in 1992 and increased to AUD 1,216.4 billion in 2010. PBS expenditure on statins decreased from 2011 onwards and accounted for AUD 645.6 million of total PBS expenditure in 2013 (Figure 1). In 2013, atorvastatin accounted for the greatest proportion of PBS statin expenditure, followed by rosuvastatin and simvastastin. 
Figure 1 - Total PBS expenditure on statins 1992 - 2013 (in 2013 AUD)

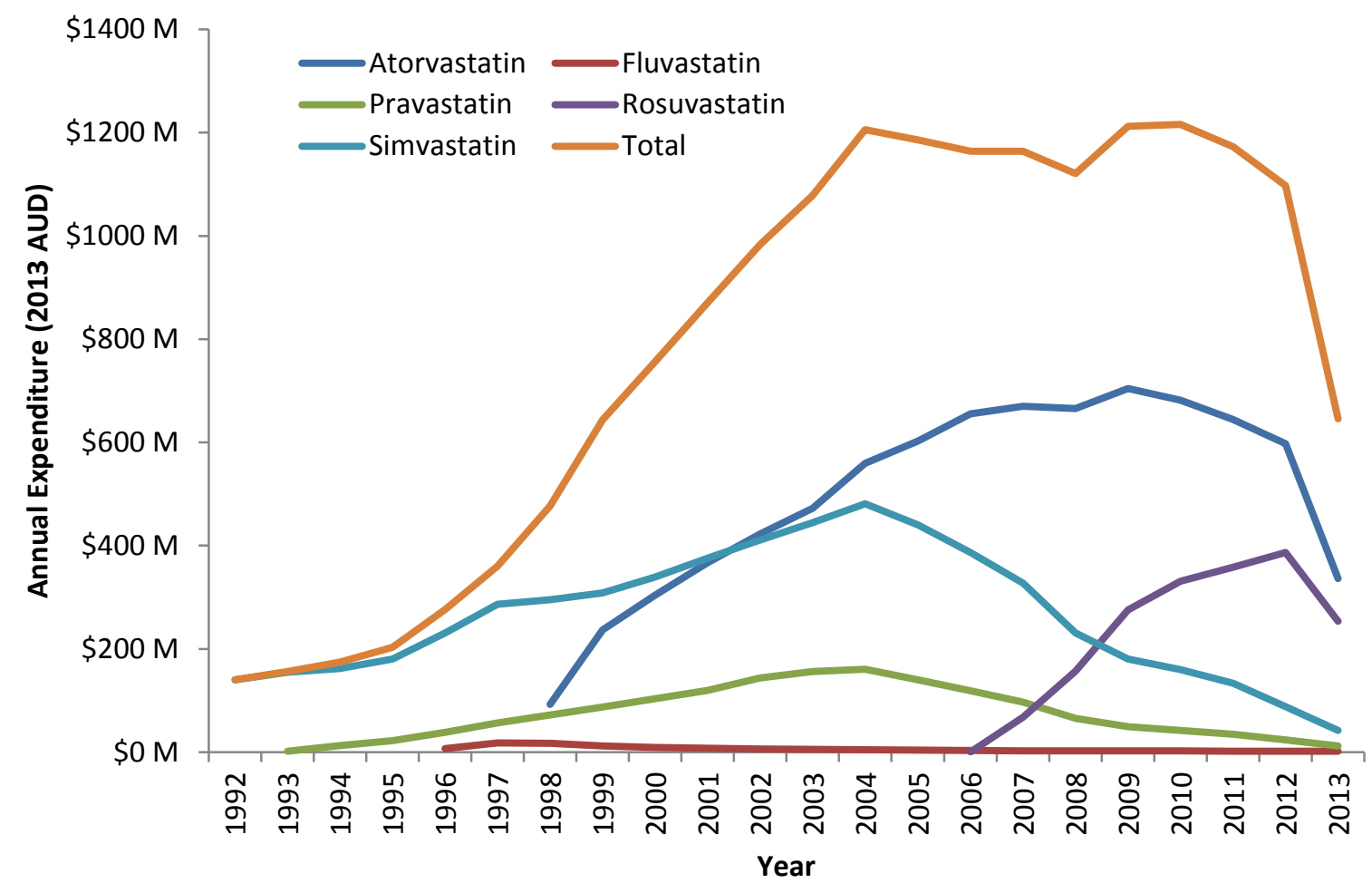


Drivers of PBS statin expenditure

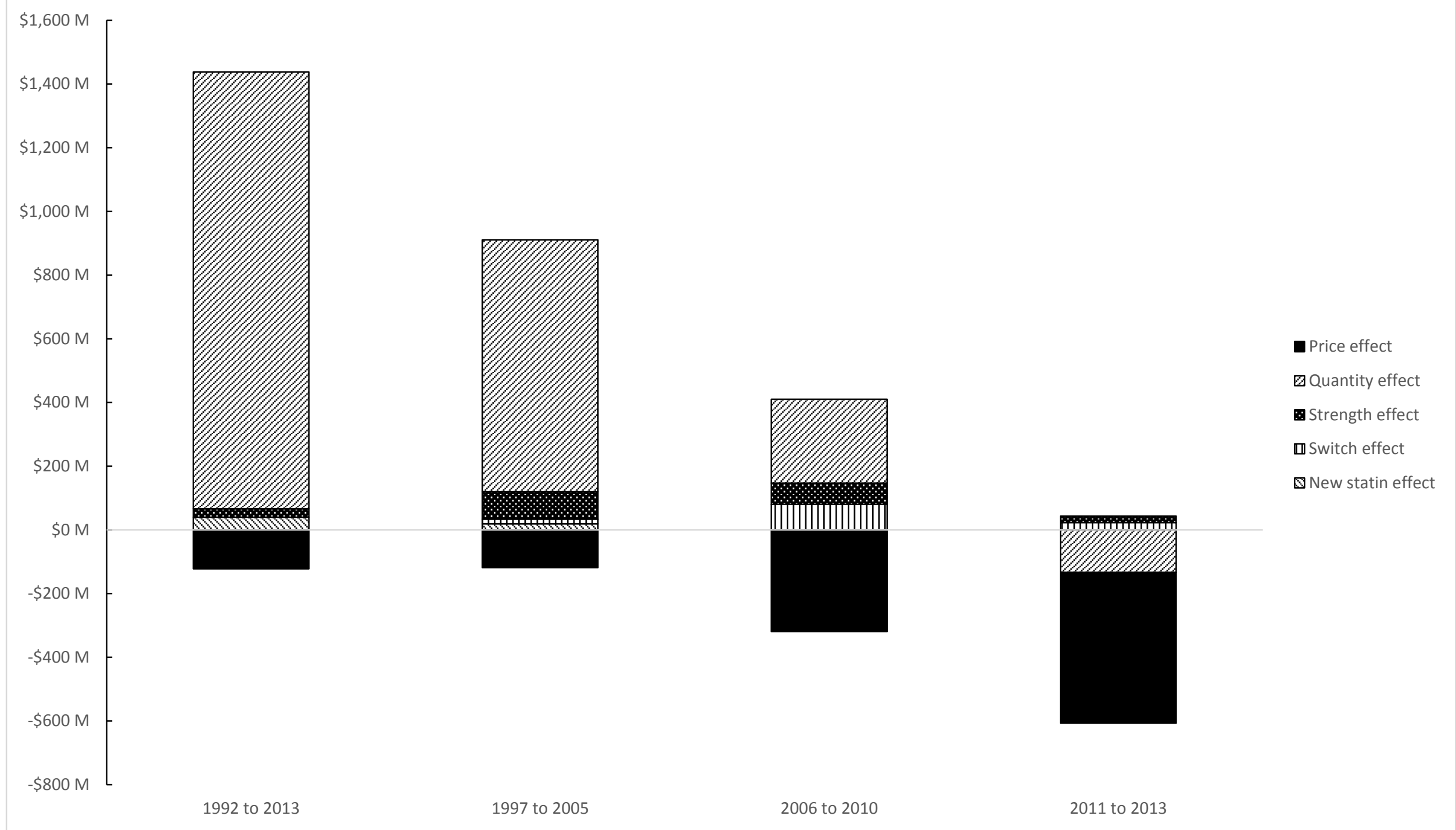

Figure 2 - Drivers of PBS statin expenditure 1992 to 2013 and three shorter periods 
- Drivers of statin expenditure

Drivers of PBS statin expenditure from January 1992 to December 2013

Over the whole study period, the largest driver was the increased quantity of statins dispensed on the PBS. The largest negative driver was the average expenditure per prescription on statins. This decreased as a result of an inflation-adjusted fall in the price of statins. There is no switching effect over the study period because simvastatin was the only statin available at the beginning of the study period. The other effect that was seen was the new statin effect which accounted for $1.9 \%$ of the total drivers increasing statin expenditure (Figure 2)

Drivers of PBS statin expenditure from January 1997 to December 2005

The growth overall in total PBS statin expenditure from 1997 and 2005 was predominantly explained by the increased volume of statins dispensed via the PBS. The next factor that impacted upon total expenditure increases over this time period was the increase in the strengths of the statins dispensed on the PBS, followed by the introduction of new statins on the PBS and then changes in the utilisation of statins. Over this period, the introduction of atorvastatin, and of new strengths of pravastatin and simvastatin on the market accounted for an increase of $\$ 19.0$ million (AUD 2013) adjusted for inflation compared to the other statins. From 1997 to 2005, the cost of statins to the government decreased overall in real terms and was the only negative driver for expenditure, accounting for $\$ 106.4$ million (AUD 2013).

\section{Drivers of PBS statin expenditure from January 2006 to December 2010}

From 2006 to 2010, the largest positive driver for PBS expenditure on statins was the increased quantity dispensed, accounting for \$263.1 million (in 2013 AUD) overall in increased expenditure. The switch effect from cheaper statins with generics available on the PBS to more expensive patent protected statins was the second largest positive driver of PBS expenditure on statins, followed by the increased strengths dispensed for patients. In contrast, the entry of new statins on the PBS and the subsequent decrease in use of other statins and average Government expenditure were negative cost drivers over the period.

\section{Drivers of PBS statin expenditure from January 2011 to December 2013}

The sum of the effects driving down statin expenditure from 2011 to 2013 was a total of $\$ 563.5$ million (AUD 2013) overall adjusted for inflation. The majority of the decrease in total statin expenditure was due to a decrease in prices ( $\$ 473.2$ million) and there was also a decrease in the volume of statins reimbursed (\$133.7 million). Changes to the relative proportion of different statins dispensed and the strengths of statins reimbursed led to relatively small increases of AUD 22.9 million and AUD 20.5 million (in AUD 2013) respectively. 
- Use of statins

From 1992 to 2012, there was a substantial and sustained increase in the total utilisation of statins on the PBS (from 3.59 DDD/1000/day in 1992 to 142.9 DDD/1000/day in 2012). This equates to a compounded annual growth rate of $20.2 \%$ over this period, and reflects both an introduction of new medicines on the PBS as well as increasing strengths prescribed to patients. In 2013, there was a decrease in the total utilisation of statins on the PBS of almost $17 \%$ (to 119.2 DDD/1000/day) (Figure $3)$.

When atorvastatin was originally listed on the PBS in 1998, it accounted for $23.7 \%$ of total statin utilisation in that calendar year. By 2013 , atorvastatin and rosuvastatin accounted for $83.2 \%$ of total statin utilisation on the PBS. The total number of statin prescriptions which were subsidised by the PBS grew from 1.8 million prescriptions in 1992 to 25.3 million prescriptions in 2012. In 2013, there was a decrease of $18.2 \%$ for PBS subsidised statins (20.7 million prescriptions). Fluvastatin utilisation on the PBS has been lower than other statins. This may in part be due to fluvastatin being considered to be a statin with lower potency in addition to there being less data showing cardiovascular benefits compared to the other statins [57]. A sensitivity analysis was conducted on utilisation by substituting historical DDDs for each statin. This showed a higher trend for utilisation up to 2009, where utilisation for atorvastastin and simvastatin halved compared to the base case results (as their DDD doubled from $10 \mathrm{mg}$ to $20 \mathrm{mg}$ and from $15 \mathrm{mg}$ to $30 \mathrm{mg}$ respectively). Similarly, fluvastatin and pravastatin utilisation decreased in 2009 as their DDDs increased.

Figure 3 - Total utilisation of statins on the PBS (in year 2009 DDD/1000/day)

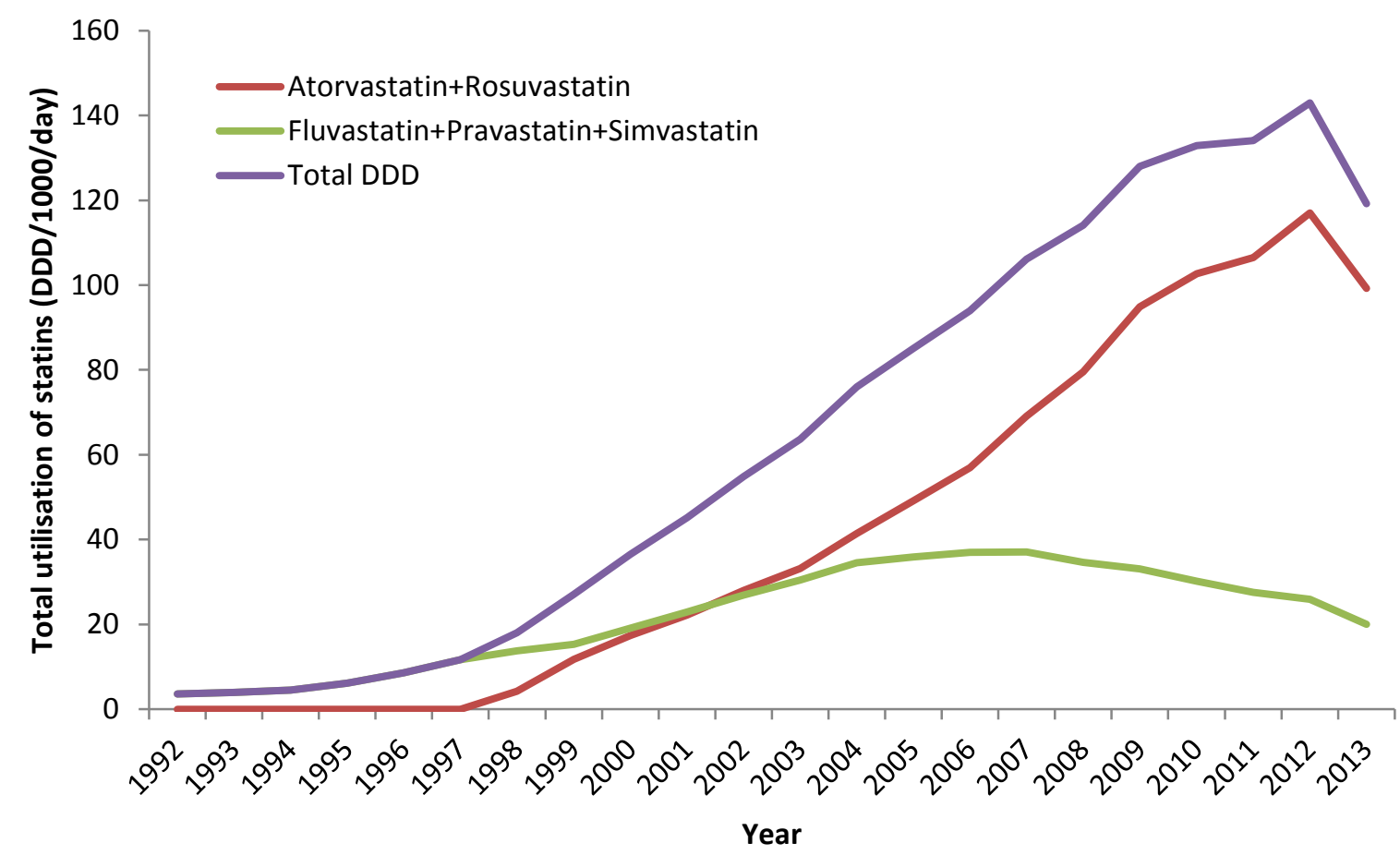


- Average PBS expenditure on statins between 1992 and 2013

PBS expenditure per statin prescription increased for all statins from the first listing until 2005 (Figure 4). There were three price reduction dates, the first in August 2005 (12.5\% price reduction for simvastatin and pravastatin due to new generic brands being listed), the second in August 2007 (20\% price reduction offered by manufacturers) and the third in April 2012 (around 50\% price reduction for generic statins as the result of the first price disclosure cycle and $16 \%$ price reduction for atorvastatin and rosuvastatin due to new generic brands being listed). These events resulted in a statistically significant decrease in expenditure per prescription for simvastatin and pravastatin in 2012 vs. 2005 (Table 3). Atorvastatin and rosuvastatin had one price reduction in April 2012 that resulted in a significant decrease to expenditure per prescription.

Table 3 - Slope changes of statin expenditure per prescription

\begin{tabular}{llll}
\hline & August 2005 & August 2007 & April 2012 \\
\hline Atorvastatin & No significant change & No significant change & $\begin{array}{l}-1.183( \pm 0.126) \\
p<0.0001\end{array}$ \\
\cline { 3 - 4 } Fluvastatin & No significant change & No significant change & No significant change \\
& & & \\
Pravastatin & $-0.514( \pm 0.041)$ & $-0.572( \pm 0.107)$ & $-0.792( \pm 0.313)$ \\
& $p<0.0001$ & $p<0.0001$ & $p<0.012$ \\
Rosuvastatin & N/A & N/A & $-0.794( \pm 0246)$ \\
& & & $p=0.002$ \\
Simvastatin & $-0.523( \pm 0.052)$ & $-0.628( \pm 0.099)$ & $-0.877( \pm 0.314)$ \\
& $p<0.0001$ & $p<0.0001$ & $p=0.0057$ \\
\hline
\end{tabular}




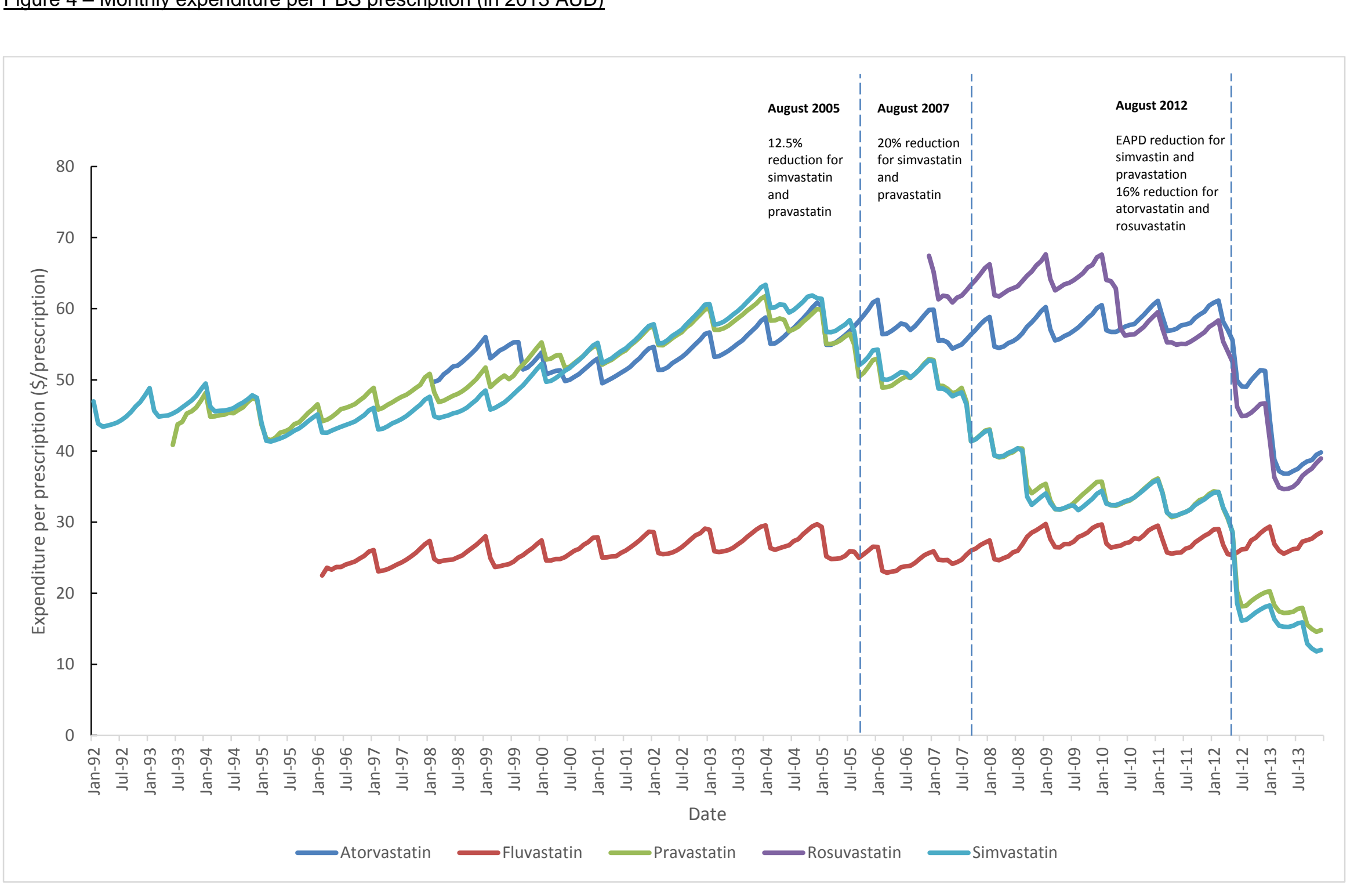


- Strength effect

Throughout the study period, there was an increase in the average strength of each statin prescribed for patients in the community (Table 4). This reflected an increase in the relative number of prescriptions for higher doses of statins compared to lower doses over the study period. On average, the strength prescribed on the PBS for atorvastatin increased by a compound rate of $4.9 \%$ per annum, fluvastatin increased by $4.0 \%$ per annum, pravastatin increased by $5.4 \%$ per annum, rosuvastatin increased by $3.2 \%$ per annum and simvastatin increased by $5.4 \%$ per annum 1 .

Table 4 - Average strength of statin dispensed on PBS (mg/prescription)

\begin{tabular}{llllll}
\hline & Simvastatin & Pravastastin & Fluvastatin & Atorvastatin & Rosuvastatin \\
\hline 1992 & 13.0 & & & & \\
1993 & 13.2 & 12.9 & & & \\
1994 & 13.2 & 13.2 & & & \\
1995 & 13.5 & 14.2 & 25.0 & & \\
1996 & 14.1 & 15.4 & 27.1 & 17.3 & \\
1997 & 15.1 & 16.5 & 28.0 & 18.6 & \\
1998 & 16.7 & 19.6 & 28.5 & 19.6 & \\
1999 & 18.3 & 22.5 & 29.4 & 20.6 & \\
2000 & 21.3 & 25.2 & 30.1 & 23.0 & \\
2001 & 23.8 & 26.8 & 30.6 & 24.9 & \\
2002 & 26.0 & 28.4 & 31.0 & 27.0 & 13.4 \\
2003 & 28.4 & 29.8 & 31.5 & 29.2 & 14.1 \\
2004 & 30.5 & 30.7 & 32.0 & 30.8 & \\
2005 & 32.1 & 31.4 & 32.8 & 31.9 & \\
2006 & 33.7 & 33.8 & 32.8 & 32.7 & \\
2007 & 35.2 & 35.5 & 40.0 & 33.4 & \\
2008 & 36.6 & 36.6 & 44.5 & 34.0 & 14.9 \\
2009 & 38.0 & 37.8 & 45.9 & 34.3 & \\
2010 & 39.1 & 38.2 & 47.2 & 34.6 & \\
2011 & 39.6 & 38.5 & 47.9 & 35.5 & \\
2012 & 39.1 & 37.8 & 48.8 & & \\
2013 & 38.9 & 37.2 & & & \\
\hline
\end{tabular}

\footnotetext{
${ }^{1}$ Compound percentage formula applied across time period where $S_{2013}=S_{t}(1+x)^{(2013-t)}$ where $S_{2013}$ is the strength of statin in $2013, S_{t}$ is the strength of statin in the year of first prescription and $x$ is the compound percentage increase.
} 


\section{Discussion}

PBS expenditure on statins has been a major contributor to the overall increase in PBS expenditure in recent years. Total PBS expenditure in the financial year ending in 2003 was $\$ 4.6$ billion nominally ( $\$ 5.9$ billion in 2013 dollars), compared to $\$ 9.0$ billion in $2013[9,10]$. PBS expenditure accounted for $0.59 \%$ and $0.58 \%$ of GDP in 2003 and 2013 respectively. The major driver for the increase in PBS expenditure for statins was the increased volume that was dispensed to patients through the PBS. The major negative driver that decreased statin expenditure over the study period was the average Government expenditure per prescription for statins. The secondary drivers that increased total PBS statin expenditure included increased strengths of statins dispensed and the choice of patent protected statins. The average Government expenditure per statin prescription has decreased with the implementation of new pricing policies since 2005 (Figure 4).

- Increased volume of statins

As would be anticipated, the largest driver of statin expenditure over the majority of the study period was the increased volume of statins dispensed on the PBS. This is similar to some European countries, as the uptake of statins to treat high cholesterol levels increased [8, 14, 17, 58-60]. Whilst volumes decreased in 2012 and 2013, the considerable growth in statin utilisation from 1992 to 2011 contributed to an appreciable increase in statin expenditure on the PBS from 1992 to 2011. Overall from 1992 to 2012, utilisation of statins on the PBS increased from 3.6 DDD/1000/year to 119.2 DDD/1000/year (Figure 3).

There have been questions raised about the appropriateness of statin prescribing in the community, where there has likely been an over-prescribing of statins to low-risk patients [61]. In the UK, statins have been shown to be cost-effective in secondary prevention compared to other treatment options [62]. In primary prevention, the cost-effectiveness ratios are dependent on a number of risk factors but still support aggressive treatment recommendations [63]. In the US, using low cost statins is costeffective for most patients with even modestly elevated cholesterol or coronary heart disease risk factors [62]. These studies suggest that the large utilisation of statins may lead to improved health outcomes for patients in the future. However, limited population-based data are available to assess the actual impact of statins on health outcomes in Australia and there may be diminishing returns.

There was a decrease in the total volume of statins dispensed on the PBS from 2011 onwards. One factor was the increasing number of prescriptions that fall under the general co-payment level and thus do not attract a Government subsidy. The price of some simvastatin and fluvastatin strengths first fell below the general co-payment in 2005, pravastastin in 2007, and atorvastatin and rosuvastatin in 2012 . These medicines are typically fully funded by patients, with the Government only subsidising the cost of medicines for general and concession patients who reach the safety net. An increasing 'under co-payment' market for statins should lead to further decreases in total government spending for statins in the future. In the financial year 2012-13, under co-payment utilisation for statins was $3.3 \%$ of the total [64]. This increased to $7.5 \%$ of total statin utilisation in 2013-14 [65].

- The price of statins

For all statins listed on the PBS, the average Government expenditure per PBS prescription after adjusting for inflation increased every year from the time they were listed up to 2005. Starting in 2005, the changes to the PBS pricing policies have been successful in reducing the average statin expenditure on the PBS [28,66]. The implementation of the PBS reforms in 2007 led to the largest decrease in the average statin expenditure to the Government. In 2012-13, the decrease in the price of statins on the PBS was the prime driver of decreased expenditure, accounting for AUD $\$ 441.9$ million in savings compared to the years prior to this.

However, there remain inefficiencies in the current PBS pricing policies, especially with regard to the extent of the initial price reductions and the length of time taken for price disclosure to become effective in reducing the prices of statins. The initial price reduction of only $16 \%$ on first listing of a generic on the PBS is lower than in other countries including France (55\% price reduction) and Austria (48\% price reduction for the first generic and $60 \%$ by the third generic) and, as previously mentioned, prices of generic simvastatin are only $2 \%$ to $4 \%$ of the prices prior to patent expiry in Netherlands, Sweden and the UK $[17,19,67,68]$ The initial price reduction effectively caps the savings for the PBS at this $16 \%$ level until price disclosure cycles are applied to these medicines. This appears inefficient compared to policies in other countries to rapidly lower generic prices, e.g. 
Sweden, enhanced by the recent instigation of monthly auctions to further lower generic prices [19, $69,70]$.

Medicines are PBS-listed on the basis of cost-effectiveness or cost minimisation compared to the existing medicine that would have been most likely to be prescribed. In 2005, the prices for simvastatin and pravastatin decreased while the prices for atorvastatin and rosuvastatin did not as they were listed in the F1 formulary, which insulated them from any price changes that may occur in the F2 formulary (which includes products with a generic available) [71]. There are no policies to maintain the incremental cost-effectiveness ratio when generic analogues of comparator medicines are introduced onto the PBS. The breakdown of reference pricing was noticeable in the case of the statins. The price differences between the presumed higher potency statins (atorvastatin and rosuvastatin) compared to simvastatin and pravastatin were not indicative anymore of the incremental cost-effectiveness ratios as calculated by the PBAC originally. This increase in the incremental costeffectiveness ratio of atorvastatin compared to simvastatin raises the question as to whether atorvastatin still remained cost-effective at the higher price compared to simvastatin. The incremental cost-effectiveness ratio would be even greater if prices for simvastatin were at levels observed in the Netherlands, Sweden and the UK once generic simvastatin became available $[8,14,17]$.

Part of the problem with obtaining low prices for generics in Australia is an operational time lag between the initial price reduction due to the listing of generics and price reductions due to price disclosure. In the case of atorvastatin, the first price reduction due to price disclosure occurred more than 20 months after the introduction of generic atorvastatin on the PBS. Price disclosure is a process that calculates price discounts available in the wholesale market and applies them to the PBS price. Because this occurs after the prices appear in the market, there is a lag time where the PBS price is more expensive than the wholesale price [72]. Interestingly, in April 2014, the PBS adopted a shorter period of time between price disclosure cycles to revise the prices of medicines twice a year as opposed to once a year as had been the case, but the time lag can still lead to missed savings [72]. However, even when allowing for this, prices of generic statins appear appreciably higher than in the Netherlands, Sweden and the UK.

Another factor which led to decreases in government spending on statins is patient co-payment. In Australia, the co-payment is increased every year in line with inflation, except in 2005 when the copayment was increased by $24 \%$. Increases in patient co-payment and decreasing prices of medicines due to PBS pricing policies have led to an increase in the number of medicines which fall into the 'under co-payment 'market as shown by the decrease in total utilisation and government expenditure on statins in 2013. However, co-payment increases may have an impact on the patient's ability to afford medicines and thus may have an adverse effect on the patient's health [73].

Conversely, lower co-payments enhance patient adherence across disease categories including statins to improve future care $[23,74,75]$. Patient co-payments could be appreciably reduced in Australia if policies were implemented to obtain lower prices for generics and enhance their utilisation compared to patented statins, as seen among a number of European countries $[8,14,17,22]$.

- Use of patent-protected statins

In December 2004, simvastatin was the first statin to lose patent protection, followed by pravastatin in December 2005. The preferential use of the new, patented, statins atorvastatin and rosuvastatin with higher prices was the second major reason for the increase in total statin expenditure on the PBS from 1998 to 2011. This may have been aided by comments from the PBAC endorsing the prescribing of atorvastatin and rosuvastatin on the basis that atorvastatin and rosuvastatin had been shown to be more effective in reducing LDL-cholesterol levels [36]. However, other sources have claimed that there is no strong evidence that these statins are better than simvastatin or pravastatin in improving population health outcomes by reducing cardiovascular morbidity [20, 21, 76-78]. Australian clinical guidelines have never specified that one statin should be used in preference to another in the treatment of hypercholesterolemia to prevent cardiovascular events [79-81]. We are not aware of any research conducted to determine whether Australian prescribers follow these guidelines when prescribing statins. However, the increase in the volume of statins prescribed over the study period shows that the management of dyslipidemia in patients is highly prevalent in Australia.

Other factors may also affect the utilisation of the more expensive statins on the PBS. Interactions between the pharmaceutical industry and prescribers may influence prescribing habits and the choice 
of therapy for patients [82]. Concern has been raised about the role of manufacturers in promoting the use of patent-protected medicines at a time when off-patent medicines are available to the market, coupled with the fact that probably the only companies marketing to physicians are those with patented products [83]. A similar high rate of atorvastatin and rosuvastatin utilisation versus generic statins was seen in Ireland where there are few demand-side measures compared with those European countries having multiple measures to encourage the preferential prescribing of generic over patented statins $[8,14,17,22,84]$. Cost-effectiveness is an important factor that is taken into consideration when medicines are initially listed on the PBS. Beyond this initial consideration, it is arguable that cost-effectiveness is not a prominent feature of the culture of medicines use in Australia. Educating and incentivising prescribers to use cheaper and more cost-effective medicines might lead to long term savings on medicines expenditure. Providing incentives for prescribers to preferentially prescribe cheaper off-patent medicines could also lead to substantial savings to the Australian health care system.

The role of pharmacists in promoting the use of off-patent medicines is influenced by co-payment levels and the price they can negotiate for generic medicines. Pharmacies can negotiate positive trading terms for generic medicines compared to originator brands, which presents them with a financial incentive to substitute generic medicines [85]. The maximum price that patients pay for medicines is set at the co-payment. However, there are brand price premiums for originator brands of simvastatin and pravastatin, where patients have to pay more for these originators.

The reimbursement price that the Government pays for medicines is the same regardless of whether a medicine is generic or an originator brand. Creating a reimbursement price difference for the Government, or providing a price incentive for patients to purchase generic medicines, could be beneficial for reducing PBS pharmaceutical expenditure and increasing utilisation of generic medicines.

\section{- Strength of statins}

Another finding was the increasing prescribing of higher strengths of statins over time (Table 3), potentially reflecting the implementation of clinical guidelines suggesting tighter cholesterol control for patients [81]. Prescribed doses of statins have been found to vary considerably across countries. In a recent cohort study in Finland, patients prescribed statins for the first time were typically initiated with either $10 \mathrm{mg}$ or $20 \mathrm{mg}$ simvastatin (94\% of the cohort) [86]. In addition, a considerable proportion of patients initiated on statin therapy with less potent doses remained at the initial dose after 1 year. This suggested underdosing was common, even among patients with high cardiovascular risk [86]. Similar findings were seen in Ireland, the Netherlands and the Stockholm Metropolitan Healthcare Region, Sweden, with the average dose of simvastatin prescribed for secondary prevention in Ireland at $22 \mathrm{mg}$ $[19,87]$. In the Netherlands, many patients have been prescribed starting doses at just over $15 \mathrm{mg}$ of simvastatin [88]. However, this is changing with recent guidelines advocating patients be started on higher strength statins with subsequent monitoring of prescriptions [17]. In Stockholm, the average prescribed dose of simvastatin was $20.4 \mathrm{mg}$, with an appreciable proportion of patients prescribed only $10 \mathrm{mg}$ simvastatin $[8,19]$. There was also variable dosing of statins among the different regions in Norway as well as among insured populations in South Africa [89, 90]. On the other hand, there has been an appreciable increase in the prescribing of higher strength statins in the UK following the publication of studies such as the Heart Protection Study guidelines advocating 40mg simvastatin as well as physicians being incentivised to treat patients according to agreed lipid levels $[8,91]$.

\section{- Limitations}

Some limitations should be recognised. Applying the driver methodology across the 1992 to 2013 period leads to cross effects which can influence the results. Whilst each driver is analysed separately, there are cross effects due to the presence of two or more drivers. The large change in both volume and price when comparing 2013 to 1992 has led to large cross effects which are not presented as they do not represent the effect of an individual driver. However, these cross effects may have an impact on the overall analysis of drivers.

By segregating each effect separately, this study tries to quantify the true effect of each driver while acknowledging that cross effects also have an impact on the changes in PBS expenditure on statins. Furthermore, the under co-payment market was not included. Under co-payment medicines are cheaper than those subsidised on the PBS and tend to contain lower strength statins. However, the under co-payment market represents a small proportion of total statin utilisation and does not have a large impact on Government expenditure. The under co-payment accounted for $3.3 \%$ and $7.5 \%$ of 
total utilisation for statins in Australia in 2012-13 and 2013-14 respectively [64, 65]. The under copayment market for statins should increase in the future as price disclosure continues to drive down the reimbursement price for statins. This should lead to decreased Government spending on less expensive statins as their cost is borne by patients.

Utilisation data were taken from publicly available PBS Item Reports which count services and not tablets dispensed. However, the same measure of services is used for comparisons over the study period. Patients who purchase statins through the PBS do not necessarily take their medicines but this could not be taken into account in this study.

\section{Conclusion}

In Australia, the increase in inflation-adjusted statin expenditure over time has been a result of increased utilisation generally, increased relative utilisation of more expensive statins and increased strengths prescribed to patients. This increased expenditure on statins has been counteracted by an inflation-adjusted decrease in the price of statins on the PBS over the study period. While there is still scope for greater price reductions, the changes to the PBS pricing policies have decreased the prices of generic medicines in recent years. Limitations on the power of policies to support the use of generic statins over patented statins may have contributed to excess expenditure. Demand side policies encouraging the utilisation of cheaper medicines which deliver the same health outcomes as their more expensive alternatives should be a priority. This should increase value for money on the PBS and lead to savings within the health budget, which could be reallocated to other important areas of health care.

\section{Key issues}

- Statins are the class with the highest utilisation and expenditure in Australia.

- The major driver for increased expenditure on statins in Australia was increased utilisation, followed by the relative utilisation of more expensive statins and increasing strengths of statins dispensed.

- When adjusted for inflation, expenditure per prescription of statins in Australia was the major negative driver for total expenditure.

- Pricing policies introduced in Australia have been effective in reducing the prices paid for generic medicines. Total expenditure on statins has decreased in recent years as a result of decreases to the prices for statins that have lost patent protection; however, expenditure on statins would have been appreciably lower in Australia with prices of generic statins similar to those seen in some European countries

- The utilisation of patent protected statins shows one example of utilisation of newer and more expensive medicines leading to higher total expenditure. This can be addressed through measures to encourage the preferential prescribing of generic statins first line

\section{Financial interests}

The authors declare that we have no competing interests. No writing assistance was used in preparing this manuscript.

\section{Acknowledgements}

We thank Elena Lunga, Manager, Canadian National Prescription Drug Utilization Information System for her assistance in applying the cost driver analysis to the data.

\section{References}

1. Australian Bureau of Statistics. 3303.0 - Causes of Death, Australia, 2013. Available from: http://www.abs.gov.au/ausstats/abs@.nsf/Lookup/by\%20Subject/3303.0 2013 Main\%20Features Le ading\%20Causes\%20of\%20Death 10001. [Accessed 25 June 2015]

2. Organisation for Economic Co-operation and Development. Health at a Glance 2013: OECD Indicators. 2013; Available from: http://www.oecd.org/els/health-systems/Health-at-a-Glance-2013.pdf [Accessed 15 June 2015]

3. Baigent C, Keech A, Kearney PM, Blackwell L, Buck G, Pollicino C et al. Efficacy and safety of cholesterol-lowering treatment: prospective meta-analysis of data from 90,056 participants in 14 randomised trials of statins. Lancet, 2005. 366(9493): p. 1267-78. 
4. Cholesterol Treatment Trialists' (CTT) Collaborators, Kearney PM, Blackwell L, Collins R, Keech A, Simes J, Peto R, Armitage J, Baigent C. Efficacy of cholesterol-lowering therapy in 18,686 people with diabetes in 14 randomised trials of statins: a meta-analysis. Lancet, 2008. 371(9607): p. 117-25.

5. Pedersen TR, Kjekshus J, Berg K, Haghfelt T, Faergeman O, Faergeman G, Pyörälä K, Miettinen T, Wilhelmsen L, Olsson AG, Wedel H; Scandinavian Simvastatin Survival Study Group. Randomised trial of cholesterol lowering in 4444 patients with coronary heart disease: the Scandinavian Simvastatin Survival Study (4S). 1994. Atheroscler Suppl, 2004. 5(3): p. 81-7. 6. Collins R, Armitage J, Parish S, Sleigh P, Peto R; Heart Protection Study Collaborative Group. MRC/BHF Heart Protection Study of cholesterol-lowering with simvastatin in 5963 people with diabetes: a randomised placebo-controlled trial. Lancet, 2003. 361(9374): p. 2005-16.

7. Graham I, Atar D, Borch-Johnsen K, Boysen G, Burell G, Cifkova R, Dallongeville J, De Backer $\mathrm{G}$ et al. European guidelines on cardiovascular disease prevention in clinical practice: executive summary: Fourth Joint Task Force of the European Society of Cardiology and Other Societies on Cardiovascular Disease Prevention in Clinical Practice (Constituted by representatives of nine societies and by invited experts). Eur Heart J, 2007. 28(19): p. 2375-414.

8. Bennie M, Godman B, Bishop I, Campbell S. Multiple initiatives continue to enhance the prescribing efficiency for the proton pump inhibitors and statins in Scotland. Expert Rev Pharmacoecon Outcomes Res, 2012. 12(1): p. 125-30.

9. $\quad$ PBS Information Management Section Pharmaceutical Policy Branch. Expenditure and prescriptions twelve months to 30 June 2013. 20139 June 2014]; Available from:

http://www.pbs.gov.au/statistics/2012-2013-files/expenditure-and-prescriptions-12-months-to-30-062013.pdf [Accessed 9 June 2014]

10. Pharmaceutical Pricing Section Pharmaceutical Benefits Branch. Expenditure and prescriptions twelve months to 30 June 2013. 20033 March 2015]; Available from: http://www.pbs.gov.au/statistics/2002-2003-files/expenditure-and-prescriptions-2002-03.pdf [Accessed 3 March 2015]

11. Committee for Economic Development of Australia, Healthcare: Reform or ration. 2013: Melbourne. Available from URL:

http://adminpanel.ceda.com.au/FOLDERS/Service/Files/Documents/15366 healthcarefinal1.pdf [Accessed 8 August 2015]

12. Duckett SJ. Australia's bad drug deal: high pharmaceutical prices. 2013, Grattan Institute: Melbourne. Available at URL: http://grattan.edu.au/wp-

content/uploads/2014/04/Australias_Bad_Drug_Deal_FINAL.pdf [Accessed 5 August 2015]

13. Clarke PM, Fitzgerald EM. Expiry of patent protection on statins: effects on pharmaceutical expenditure in Australia. Med J Aust, 2010. 192(11): p. 633-6.

14. Godman B, Shrank W, Andersen M, Berg C, Bishop I, Burkhardt T, Garuoliene K, Herholz H, Joppi $R$, et al. Comparing policies to enhance prescribing efficiency in Europe through increasing generic utilization: changes seen and global implications. Expert Rev Pharmacoecon Outcomes Res, 2010. 10(6): p. 707-22.

15. Jackevicius CA, Chou MM, Ross JS, Shah ND, Krumholz HM. Generic atorvastatin and health care costs. The New England journal of medicine, 2012. 366(3): p. 201-4.

16. Godman B, Schwabe U, Selke G, Wettermark B. Update of recent reforms in Germany to enhance the quality and efficiency of prescribing of proton pump inhibitors and lipid-lowering drugs. Pharmacoeconomics, 2009. 27(5): p. 435-8.

17. Woerkom M, Piepenbrink H, Godman B, Metz Jd, Campbell S, Bennie M, Eimers M, Gustafsson LL. Ongoing measures to enhance the efficiency of prescribing of proton pump inhibitors and statins in The Netherlands: influence and future implications. J Comp Eff Res, 2012. 1(6): p. 52738.

18. Andersson K, Sonesson C, Petzold M, Carlsten A, Lönnroth K. What are the obstacles to generic substitution? An assessment of the behaviour of prescribers, patients and pharmacies during the first year of generic substitution in Sweden. Pharmacoepidemiol Drug Saf, 2005. 14(5): p. 341-8. 19. Godman B, Wettermark B, Hoffmann M, Andersson K, Haycox A, Gustafsson LL. Multifaceted national and regional drug reforms and initiatives in ambulatory care in Sweden: global relevance. Expert Rev Pharmacoecon Outcomes Res, 2009. 9(1): p. 65-83.

20. Pedersen TR, Faergeman O, Kastelein JJ, Olsson AG, Tikkanen MJ, Holme I, Larsen ML, et al. High-dose atorvastatin vs usual-dose simvastatin for secondary prevention after myocardial infarction: the IDEAL study: a randomized controlled trial. JAMA, 2005. 294(19): p. 2437-45. 21. Weng TC, Yang YH, Lin SJ, Tai SH. A systematic review and meta-analysis on the therapeutic equivalence of statins. J Clin Pharm Ther, 2010. 35(2): p. 139-51. 
22. Moon JC, Bogle RG. Switching statins. BMJ, 2006. 332(7554): p. 1344-5.

23. Gagne JJ, Choudhry NK, Kesselheim AS, Polinski JM, Hutchins D, Matlin OS, Brennan TA, Avorn J, Shrank WH. Comparative effectiveness of generic and brand-name statins on patient outcomes: a cohort study. Ann Intern Med, 2014. 161(6): p. 400-7.

24. Knott RJ, Petrie DJ, Heeley EL, Chalmers JP, Clarke PM. The effects of reduced copayments on discontinuation and adherence failure to statin medication in Australia. Health Policy, 2015. 119(5): p. 620-7.

25. Clarke PM. The pricing of statins and implications for Pharmaceutical Benefits Scheme expenditure. The Medical journal of Australia, 2013. 198(5): p. 260.

26. Australian Government Department of Health and Ageing. Pharmaceutical Benefits Scheme Explanatory Notes. 2013. Available from: http://pbs.gov.au/info/healthpro/explanatorynotes/section1/Section_1_4_Explanatory_Notes [Access 12 May 2015]

27. Australian Government Department of Health and Ageing. Browse by Therapeutic Group. 2013. Available from: http://www.pbs.gov.au/browse/therapeutic-group [Accessed 12 July 2015] 28. Australian Government Department of Health and Ageing, The Impact of PBS Reform. 2010: Canberra. Available at URL: http://www.health.gov.au/internet/main/publishing.nsf/Content/pbsreform-report [Accessed 12 July 2015]

29. National Prescribing Service, NPS News 76. Generic medicines: informing patients about multiple brands. 2011: Sydney. Available from URL: http://www.nps.org.au/publications/healthprofessional/nps-news/2011/generic-medicines-informing-patients [Accessed 28 July 2015] 30. Wettermark B, Godman B, Jacobsson B, Haaijer-Ruskamp FM. Soft regulations in pharmaceutical policy making: an overview of current approaches and their consequences. Appl Health Econ Health Policy, 2009. 7(3): p. 137-47.

31. Garuoliene K, Alonderis T, Marcinkevic ius M. Pharmaceutical policy and the effects of the economic crisis: Lithuania. EuroHealth, 2011. 17: p. 1-4.

32. Voncina L, Strizrep T, Godman B, Bennie M, Bishop I, Campbell S, Vlahović-Palčevski V, Gustafsson LL. Influence of demand-side measures to enhance renin-angiotensin prescribing efficiency in Europe: implications for the future. Expert Rev Pharmacoecon Outcomes Res, 2011. 11(4): p. 469-79.

33. Godman B, Malmström RE, Diogene E, Jayathissa S, McTaggart S, Cars T, Alvarez-Madrazo $S$ et al. Dabigatran - a continuing exemplar case history demonstrating the need for comprehensive models to optimize the utilization of new drugs. Front Pharmacol, 2014. 5: p. 109.

34. Godman B., Bishop I, Finlayson AE, Campbell S, Kwon HY, Bennie M. Reforms and initiatives in Scotland in recent years to encourage the prescribing of generic drugs, their influence and implications for other countries. Expert Rev Pharmacoecon Outcomes Res, 2013. 13(4): p. 46982.

35. Moon JC, Godman B, Petzold M, Alvarez-Madrazo S, Bennett K, Bishop I, et al. Different initiatives across Europe to enhance losartan utilization post generics: impact and implications. Front Pharmacol, 2014. 5: p. 219.

36. Australian Government Department of Health and Ageing. Review of Statin Therapies. 2012. Available at URL: Available from: http://www.pbs.gov.au/info/industry/listing/elements/pbacmeetings/psd/2012-07/review-of-statin-therapies [Accessed 12 July 2015]

37. Australian Government Department of Health and Ageing. Public Summary Documents by Product Rosuvastatin Calcium, tablets, $5 \mathrm{mg}, 10 \mathrm{mg}, 20 \mathrm{mg}, 40 \mathrm{mg}$, Crestor®, July 2006. Available from: http://www.health.gov.au/internet/main/publishing.nsf/Content/pbac-psd-rosuvastatin-july06.

38. Australian Government Department of Health and Ageing. Schedule of Pharmaceutical Benefits for Approved Pharmacists and Medical Practitioners. 2005. Available from: http://www.pbs.gov.au/publication/schedule/2005/2005-12-01-general-schedule.pdf [Accessed 15 August 2015]

39. Australian Government Department of Health and Ageing. Schedule of Pharmaceutical Benefits. 2012. Available from: http://www.pbs.gov.au/publication/schedule/2012/04/2012-04-01general-schedule.pdf [Accessed 15 January 2015]

40. Australian Government Department of Human Services. Pharmaceutical Benefits Schedule Item Reports. 2015. Available from:

http://medicarestatistics.humanservices.gov.au/statistics/pbs_item.jsp [Accessed 11 January 2015]

41. Australian Government Department of Human Services. Pharmaceutical Benefits Schedule Item Reports. 2014. Available from: https://www.medicareaustralia.gov.au/statistics/pbs_item.shtml [Accessed 6 March 2014]

42. Australian Bureau of Statistics. 6401.0 - Consumer Price Index, Australia, Dec 2013.

Available from: 
http://www.abs.gov.au/AUSSTATS/abs@.nsf/Lookup/6401.0Main+Features1Dec\%202013?OpenDoc ument [Accessed 2 August 2014]

43. Patented Medicine Prices Review Board, The Drivers of Prescription Drug Expenditure - A Methodological Report. 2013: Ottowa, Ontario, Canada. Available via URL: http://www.pmprbcepmb.gc.ca/CMFiles/NPDUIS/NPDUIS_Drivers_Prescription_Drug_Expenditures_2013-12-

13_EN.pdf [Accessed 12 July 2015]

44. Australian Government Department of Health and Ageing, Australian Statistics on Medicines 2010. Canberra, Australia. Available from URL: http://www.pbs.gov.au/info/statistics/asm/asm-2010 [Accessed 2 July 2015]

45. WHO. Introduction to Drug Utilisation Research. WHO International Working Group for Drug Statistics Methodology, WHO Collaborating Centre for Drug Statistics Methodology, WHO Collaborating Centre for Drug Utilization Research and Clinical Pharmacological Services. Available from URL:

http://www.who.int/medicines/areas/quality_safety/safety_efficacy/Drug\%20utilization\%20research.pd $f$ [Accessed 2 July 2015]

46. WHO Collaborating Centre for Drug Statistics Methodology. ATC/DDD Index 2014. Available from: http://www.whocc.no/atc_ddd_index/ [Access 2 April 2014]

47. Ronning M. A historical overview of the ATC/DDD methodology. WHO Drug Information, 2002. 16(3): p. 233-234.

48. Vlahovic-Palcevski V, Gantumur M, Radosević N, Palcevski G, Vander Stichele R. Coping with changes in the Defined Daily Dose in a longitudinal drug consumption database. Pharmacy world \& science : PWS, 2010. 32(2): p. 125-9.

49. Australian Bureau of Statistics. 3101.0 - Australian Demographic Statistics, Dec 2013.

Available from:

http://www.abs.gov.au/AUSSTATS/abs@.nsf/allprimarymainfeatures/FA627CA7C5708380CA257D5 D0015EB95?opendocument [Accessed 5 May 2014]

50. Cochrane Effective Practice and Organisation of Care Review Group. Interrupted time series (ITS) analyses. 2013. Available from:

http://epoc.cochrane.org/sites/epoc.cochrane.org/files/uploads/21\%20Interrupted\%20time\%20series \%20analyses\%202013\%2008\%2012_1.pdf [Accessed 10 October 2014]

51. Grimshaw J, Campbell M, Eccles M, Steen N. Experimental and quasi-experimental designs for evaluating guideline implementation strategies. Fam Pract, 2000. 17 Suppl 1: p. S11-6.

52. Harris AD, McGregor JC, Perencevich EN, Furuno JP, Zhu J, Peterson DE, Finkelstein J. The use and interpretation of quasi-experimental studies in medical informatics. J Am Med Inform Assoc, 2006. 13(1): p. 16-23.

53. Ramsay CR, Matowe L, Grilli R, Grimshaw JM, Thomas RE. Interrupted time series designs in health technology assessment: lessons from two systematic reviews of behavior change strategies. Int J Technol Assess Health Care, 2003. 19(4): p. 613-23.

54. Eccles M, Grimshaw J, Campbell M, Ramsay C Research designs for studies evaluating the effectiveness of change and improvement strategies. Qual Saf Health Care, 2003. 12(1): p. 47-52.

55. Jandoc R, Burden AM, Mamdani M, Lévesque LE, Cadarette SM. Interrupted time series analysis in drug utilization research is increasing: systematic review and recommendations. Journal of clinical epidemiology, 2015. 68(8): p. 950-6.

56. Penfold RB, Zhang $\mathrm{F}$. Use of interrupted time series analysis in evaluating health care quality improvements. Acad Pediatr, 2013. 13(6 Suppl): p. S38-44.

57. Kapur NK, Musunuru K. Clinical efficacy and safety of statins in managing cardiovascular risk. Vasc Health Risk Manag, 2008. 4(2): p. 341-53.

58. Zeng W, XiH, Godman B, Finlayson AE, Malmstrom RE. Ongoing initiatives to improve prescribing efficiency in China; statins as a case history Generics and Biosimilars Initiative Journal, 2014. 3(3): p. 122-32.

59. Fraeyman J, Van Hal G, Godman B, Beutels P. The potential influence of various initiatives to improve rational prescribing for proton pump inhibitors and statins in Belgium. Expert Rev

Pharmacoecon Outcomes Res, 2013. 13(1): p. 141-51.

60. Kwon HY, Hong JM, Godman B, Yang BM. Price cuts and drug spending in South Korea: the case of antihyperlipidemic agents. Health Policy, 2013. 112(3): p. 217-26.

61. Smith J. Appropriate primary prevention of cardiovascular disease: does this mean more or less statin use? Australian Prescriber, 2011. 34(6): p. 169-172.

62. Lazar LD, Pletcher MJ, Coxson PG, Bibbins-Domingo K, Goldman L. Cost-effectiveness of statin therapy for primary prevention in a low-cost statin era. Circulation, 2011. 124(2): p. 146-53. 
63. Ward S, Lloyd Jones M, Pandor A, Holmes M, Ara R, Ryan A, Yeo W, Payne N. A systematic review and economic evaluation of statins for the prevention of coronary events. Health Technol Assess. 2007 Apr;11(14):1-160

64. Australian Government Department of Health, Report to Parliament on the Collection of PBS/RPBS Under Co-payment Prescription Data 2012-13. Available at URL:

https://www.health.gov.au/internet/main/publishing.nsf/Content/14DEA08914F167C0CA257BF0001C 96FC/\$File/report-on-collection-pbs-under-co-payments-2012-13.pdf [Accessed 15 February 2015] 65. Australian Government Department of Health. Report on the Collection of Under Co-payment Data 2013-14. 2015 Available from: http://www.pbs.gov.au/info/statistics/under-co-payment/ucp-datareport [Accessed 15 February 2015]

66. Sweeny K. The Impact of Further PBS Reforms Report to Medicines Australia. 2013.

Available from URL: https://medicinesaustralia.com.au/files/2010/01/20130515-rep-The-Impact-ofFurther-PBS-Reforms-Final-report-from-CSES.pdf [Accessed 12 July 2015]

67. Sermet C, Andrieu V, Godman B, Van Ganse E, Haycox A, Reynier JP. Ongoing pharmaceutical reforms in France: implications for key stakeholder groups. Appl Health Econ Health Policy, 2010. 8(1): p. 7-24.

68. Godman B, Burkhardt T, Bucsics A, Wettermark B, Wieninger P. Impact of recent reforms in Austria on utilization and expenditure of PPIs and lipid-lowering drugs: implications for the future.

Expert Rev Pharmacoecon Outcomes Res, 2009. 9(5): p. 475-84.

69. Godman B, Persson M, Miranda J, Skiöld P, Wettermark B, Barbui C, Gustafsson LL. Changes in the utilization of venlafaxine after the introduction of generics in Sweden. Appl Health Econ Health Policy, 2013. 11(4): p. 383-93.

70. Godman B, Bennie M., Baumgärtel C, Sović Brkičić L, Burkhardt T, Fürst J et al, Essential to increase the use of generics in Europe to maintain comprehensive healthcare? Farmeconomia: Health Economics and Therapeutic Pathways 2012. 13 (Suppl 3): p. 5-20.

71. Searles A, Jefferys S, Doran E, Henry DA. Reference pricing, generic drugs and proposed changes to the Pharmaceutical Benefits Scheme. Med J Aust, 2007. 187(4): p. 236-9.

72. Australian Government Department of Health. Simplified Price Disclosure. 2013. Available from: http://pbs.gov.au/industry/pricing/price-disclosure-spd/spd-presentation-slides-13-12-2013.pdf [Accessed 12 April 2014]

73. Hynd A, Roughead EE, Preen DB, Glover J, Bulsara M, Semmens J. The impact of copayment increases on dispensings of government-subsidised medicines in Australia.

Pharmacoepidemiol Drug Saf, 2008. 17(11): p. 1091-9.

74. Shrank WH, Hoang T, Ettner SL, Glassman PA, Nair K, DeLapp D, Dirstine J, Avorn J, Asch

SM. The implications of choice: prescribing generic or preferred pharmaceuticals improves medication adherence for chronic conditions. Arch Intern Med, 2006. 166(3): p. 332-7.

75. Barbui C, Conti V. Adherence to generic v. brand antidepressant treatment and the key role of health system factors. Epidemiol Psychiatr Sci, 2014: p. 1-4.

76. Soran H, Durrington P. Rosuvastatin: efficacy, safety and clinical effectiveness. Expert Opin Pharmacother, 2008. 9(12): p. 2145-60.

77. Morrissey RP, Diamond GA, Kaul S. Statins in acute coronary syndromes: do the guideline recommendations match the evidence? J Am Coll Cardiol, 2009. 54(15): p. 1425-33.

78. Neumann A, Maura G, Weill A, Ricordeau P, Alla F, Allemand H. Comparative effectiveness of rosuvastatin versus simvastatin in primary prevention among new users: a cohort study in the French national health insurance database. Pharmacoepidemiol Drug Saf, 2014. 23(3): p. 240-50. 79. National Heart Foundation of Australia; Cardiac Society of Australia and New Zealand. Lipid management guidelines--2001. National Heart Foundation of Australia, The Cardiac Society of Australia and New Zealand. The Medical Journal of Australia, 2001. 175 Suppl: p. S57-85.

80. Tonkin A, Barter P, Best J, Boyden A, Furler J, Hossack K, Sullivan D, Thompson P, Vale M, Cooper C, et al. National Heart Foundation of Australia and the Cardiac Society of Australia and New Zealand: position statement on lipid management--2005. Heart, lung \& circulation, 2005. 14(4): p. 275-91.

81. Therapeutic Guidelines Ltd. eTG complete. 2014. Available from:

http://online.tg.org.au/ip/desktop/tgc.htm [Accessed 3 March 2014]

82. Breen KJ. The medical profession and the pharmaceutical industry: when will we open our eyes? Med J Aust, 2004. 180(8): p. 409-10.

83. Minhas R. Statin utilisation--recognising the role of the invisible hand. Int J Clin Pract, 2007. 61(1): p. 3-6.

84. Cappuccio FP. Commentary: Controversies in NICE guidance on lipid modification for the prevention of cardiovascular disease. BMJ, 2008. 336(7655): p. 1248-9. 
85. Beecroft G. Generic drug policy in Australia: a community pharmacy perspective. Australia and New Zealand health policy, 2007. 4: p. 7.

86. Kiviniemi V, Peura P, Helin-Salmivaara A, Martikainen JE, Hartikainen J, Huupponen R, Korhonen MJ. Suboptimal use of statins at treatment initiation. Eur J Clin Pharmacol, 2011. 67(9): p. 971-3.

87. Feely J, Bennett K. Epidemiology and economics of statin use. Ir Med J, 2008. 101(6): p. $188-91$.

88. Mantel-Teeuwisse AK, Klungel OH, Schalekamp T, Verschuren WM, Porsius AJ, de Boer A. Suboptimal choices and dosing of statins at start of therapy. Br J Clin Pharmacol, 2005. 60(1): p. 839.

89. Hartz I, Sakshaug S, Furu K, Engeland A, Eggen AE, Njølstad I, Skurtveit S. Aspects of statin prescribing in Norwegian counties with high, average and low statin consumption - an individual-level prescription database study. BMC Clin Pharmacol, 2007. 7: p. 14.

90. Godman B, Bishop I, Campbell SM, Malmström RE, Truter I. Quality and efficiency of statin prescribing across countries with a special focus on South Africa; findings and future implications.

Expert Rev Pharmacoecon Outcomes Res, 2014: p. 1-8.

91. McGinn D, Godman B, Lonsdale J, Way R, Wettermark B, Haycox A. Initiatives to enhance the quality and efficiency of statin and PPI prescribing in the UK: impact and implications. Expert Rev Pharmacoecon Outcomes Res, 2010. 10(1): p. 73-85. 